\title{
Freedom and the Social Contract
}

\section{The last several weeks (as of this writing) have been filled with disclosures of intelligence practices in the U.S. and elsewhere. Edward Snowden's unauthorized release}

of highly classified information has stirred a great deal of debate about national security and the means used to preserve it.

In the midst of all this, I looked to Jean-Jacques Rousseau's well-known $18^{\text {th }}$-century writings on the Social Contract (Du Contrat Social, Ou Principes du Droit Politique) for insight. Distilled and interpreted through my perspective, I took away several notions. One is that in a society, to achieve a degree of safety and stability, we as individuals give up some absolute freedom of action to what Rousseau called the sovereign will of the people. He did not equate this to government, which he argued was distinct and derived its power from the sovereign people.

I think it may be fair to say that most of us would not want to live in a society that had no limits to individual behavior. In such a society, there would be no limit to the potential harm an individual could visit upon others. In exchange for some measure of stability and safety, we voluntarily give up absolute freedom in exchange for the rule of law. In Rousseau's terms, however, the laws must come from the sovereign people, not from the government. We approximate this in most modern societies creating representative government using public elections to populate the key parts of the government.

I think it is also likely to be widely agreed that a society in which there was no privacy and every action or plan was visible to everyone might not be a place in which most of us might like to live. I am reminded, however, of my life in a small village of about 3,000 people in Germany. In the 1960s, no one had phones at home (well, very few). You went to the post office to mail letters, pick up mail, and make or receive phone calls. In some sense, the Postmaster was the most well-informed person about the doings of the town. He saw who was calling or writing to whom. There was not a lot of privacy. The modern notion of privacy may in part have derived from the growth of large urban concentrations in which few people know one another.

In today's world, threats to our safety and threats to national security come from many directions and not all or even many of them originate from state actors. If I can use the term "cyber-safety" to suggest safety while making use of the content and tools of the Internet, World Wide Web, and computing devices in general, it seems fair to say the expansion of these services and systems has been accompanied by a growth in their abuse. Moreover, it has been frequently observed that there is an asymmetry in the degree of abuse and harm that individuals can perpetrate on citizens, and on the varied infrastructure of our society. Vast harm and damage may be inflicted with only modest investment in resources. Whether we speak of damage and harm using computerbased tools or damage from lethal, homemade explosives, the asymmetry is apparent. While there remain serious potential threats to the well-being of citizens from entities we call na- tion- states, there are similarly serious potential threats originating with individuals and small groups.

Presuming we have accepted the theory that safety is partly found through voluntarily following law, we must also recognize that there are parties domestic and otherwise who wish us individual and collective harm. The societal response to this is to provide for law enforcement and intelligence gathering (domestic and non-domestic) in an attempt to detect and thwart harmful plans from becoming harmful reality. We do not always succeed.

The tension we feel between preserving privacy and a desire to be protected from harm feeds the debate about the extent to which we are willing to trade one for the other. Not everyone, nor every culture, will find the same point of equilibrium. Moreover, as technology and society evolve, the equilibrium points may shift. It has been said that "security" is not found in apprehending a guilty party but in preventing the harm from occurring. While this notion can surely be overextended, it can also be understood to justify a certain degree of intelligence gathering in the service of safety and security.

There is some irony in the fact that our privacy is more difficult than ever to preserve, given the advent of smartphones, tablets, laptops, the Web and the Internet, but that the threats against our safety and security use the same infrastructure to achieve nefarious ends. Our discipline, computer science, is deeply involved in the many dimensions of this conundrum and we owe it to our fellow citizens to be thoughtful in response and to contribute to reasoned consideration of the balance our society needs between potential policy extremes.

Vinton G. Cerf, ACM PRESIDENT 